TINA BOŽIĆ i RENATA RELJA

Sveučilište u Splitu, Filozofski fakultet Odsjek za sociologiju, Split, Hrvatska

DOI 10.5937/kultura1236085B

UDK 316.776-057.87:81'37(497.5)"2010"

316.728-057.87(497.5)

originalan naučni rad

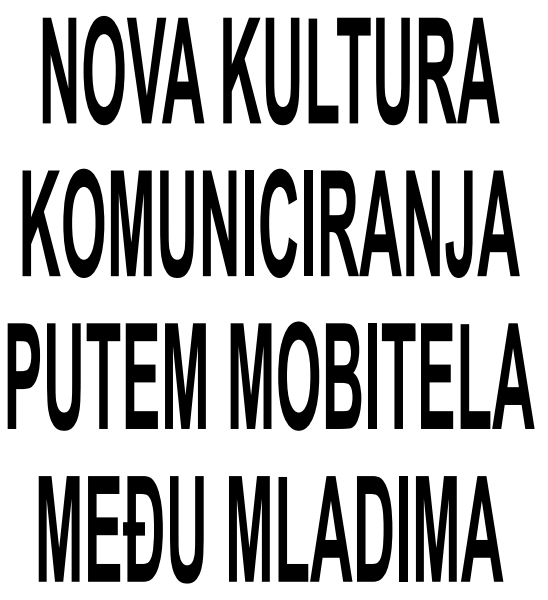

Sažetak: Rad predstavlja dio rezultata empirijskog istraživanja čiji je cilj analiza aspekata korištenja mobilnih telefona među mladima, kao $i$ utjecaja mobitela na svakodnevni društveni život, komunikaciju i interakciju. Glavni teorijsko istraživački fokus je sociološki i kulturalni fenomen korištenja mobilne telefonije među mladima, te njegov utjecaj na svakodnevni društveni život, društvene odnose, obrasce aktivnosti, komunikaciju i interakciju, stavljajući naglasak na odnos pojedinca prema uporabi mobilne telefonije. U radu se propituje kreiranje nove kulture komuniciranja, gdje se objašnjavaju fenomeni stvaranja novih lingvističkih obrazaca, redefiniranje tradicionalnog shvaćanja vremena i mjesta. Razmatrano je i pitanje privatnog i javnog, socijalno prihvatljivog, odnosno neprihvatljivog. Istraživanje je provedeno metodom ankete, na uzorku od 302 ispitanika/ca (studenata i srednjoškolaca) s područja grada Splita, te okolnih mjesta. Terenska faza istraživanja provedena je tijekom svibnja i lipnja 2010. godine. Mladi su odabrani kao istraživačka populacija jer se za njih smatra da su „pioniri“ " $u$ korištenju informacijske i računalne tehnologije, te kako su upravo oni najbolji poznavaoci vitalnih tehnoloških društvenih otkrića. Mladi ljudi su najbrojnija skupina konzumenata mobilne tehnologije, te se često smatraju začetnicima u njihovoj adaptaciji i evoluciji.

Ključne riječi: mobilna tehnologija, komunikacija, mladi, SMS, vrijeme-mjesto, privatno-javno 


\section{Uvod}

Komunikacija je oduvijek predstavljala okosnicu svakog društva, kulture i pojedinca samoga. Najkraće ju je moguće definirati kao individualno proizvođenje nekog simboličkog sadržaja u skladu s nekim kodom, koji anticipira prijem tog sadržaja kod drugih subjekata, u skladu s istim kodom. ${ }^{1}$ Neki je autori ${ }^{2}$ definiraju i kao transmisiju mišljenja, uputstava, osjećaja, želja, ideja, od jednog subjekta ka drugome.

Nove tehnologije u području elektroničkih medija i telekomunikacija nadilaze sve barijere, vremenske i prostorne, koje stoje na putu neometanoj razmjeni poruka. Novi mediji, globalni kako prema svojoj strukturi tako i prema svom djelovanju, korjenito su promjenili i mjenjaju način komunikacije. ${ }^{3}$ Krotz $^{4}$ ističe kako osim komunikacije licem u lice, danas egzistiraju još tri različite vrste posredovane komunikacije: posredovana interpersonalna komunikacija - komunikacija koja se očituje na primjeru pisanja i čitanja pisama, elektroničke pošte ili razgovora putem mobitela (telefona) s drugom osobom; komunikacija osobe s medijem - bilo da govorimo o medijskoj produkciji, u kojoj osoba piše knjigu ili snima film, ili o medijskoj recepciji, prema kojoj osoba gleda televiziju ili čita knjigu; interaktivna komunikacija - koja se događa unutar kompjuterskih igrica, s robotima poput $\mathrm{AIBO}^{5}$, navigacijski uređaji i slično. $U$ ovom slučaju onaj aktivni drugi je računalni sustav.

Gotovo svaki trenutak života provodimo komunicirajući, a o tom činu ovisi kako naš privatni, tako i društveni i radni život. Mediji su danas postali središnji čimbenik prilikom organiziranja većine aspekata suvremenog života, bez obzira govorimo li o svakodnevnim susretima s prijateljima, društvenim institucijama, kulturnim sustavima ili osobnom razumjevanju svijeta i samoga sebe. ${ }^{6}$ Komunikacija doživljava revolucionarne promjeneinternet, mobilna telefonija, internetske grupe, e-mail, mjenjaju

1 Price prema Tomić Z., Komunikacija i javnost, Beograd 2004, str. 7.

2 Gurevitch prema ibid., str. 9.

3 McQuial prema Leburić A. i Nigoević M., Mediji kao (pre)nositelji interkulturalizma u hrvatsko-talijanskim interakcijama: istraživanja s početka trećeg milenija, Split 2008, str. 97.

4 Krotz F., The meta-process of „mediatization“ as a conceptual frame, Global Media and Communication br. 3, SAGE Publication 2007, str. 258

5 Artificial Intelligence roBOt, u značenju Robot umjetne inteligencije. Aibo je autonomni robot i on je sposoban kretati se sam bez ljudske pomoći koristeći senzore za vid, te senzore za otkrivanje prepreka. Aibo je također sposoban prepoznati izgovorene naredbe, kao i prepoznati svoga vlasnika po glasu kao i po liku (http://hr.wikipedia.org/wiki/AIBO, 11.04.2012).

6 Deacon i dr. prema Leburić A., Quien M. i Lovrić D., Stari i novi mediji. sociološko istraživanje medijskog stiliziranja života, Split 2008, str. 9. 
način na koji ljudi komuniciraju, te dovode do novih oblika komuniciranja. Zahvaljujući brzom razvoju tehnologije, u procesu komunikacije događaju se važne promjene: protok informacija je ubrzan, a vremenska i prostorna ograničenja kao da više i ne postoje. Mobilna telefonija nudi pojedincima više od same slobode kretanja. Osim što su informacije na dohvat ruke, takva komunikacija postaje fleksibilnija i raznovrsnija - pluralistična u svakom mogućem smislu. Poruke nisu samo oblik pukog prenošenja informacija, moguće je i bilježenje dojmova pomoću slika, boja, zvukova, melodija,video i audio zapisa. ${ }^{7}$ Iako je u svojoj biti mobitel jednostavno sredstvo komuniciranja, on postaje dio svog korisnika, objekt kojim se prepoznajemo i identificiramo, i to ne samo od strane onih s kojima smo povezani, već i od onih koji nas vide kako ga koristimo. Mobitel danas posjeduje snažno simboličko i afektivno značenje, dakle postaje daleko više od pukog komunikacijskog alata. ${ }^{8}$ Postavlja se pitanje koliko i kako se komunikacija promijenila ulaskom novih tehnologija u našu svakodnevnicu i interakciju s drugima. U radu ćemo pokušati odgovoriti na pitanje što je novoga donio mobitel u našoj interakciji s drugima, kakva je ta nova kultura komuniciranja, kojim je novim tehnikama, oblicima izražavanja i sporazumijevanja rezultirala, koliko je promjenila tradicionalne definicije socijalno prihvatljivog ponašanja, onoga što je javno i onoga što je privatno, mjesta i vremena kakvog poznajemo.

\section{Tekstualna komunikacija}

Mobitel je uz ostale brojne funkcije i pogodnosti, iznjedrio sasvim novi način komunikacije tekstualnim porukama. Popularno nazvana $\mathrm{SMS}^{9}$ (Short Message Service) komunikacija ili tekstualna komunikacija definira se kao aktivnost sastavljanja kratkih poruka pomoću različitih slova, brojeva, interpunkcija i ostalih znakova i njihovo slanje, primanje ili izmjenjivanje među dva ili više sugovornika. Mladi se smatraju začetnicima u adaptaciji i prilagodbi tog oblika komunikacije. Smatra se kako su relativna povoljnost i dostupnost temeljni razlozi njezine adaptacije. Među mladima, ona je najpopularniji oblik interakcije koji

7 Ibid., str. 83.

8 Gordon J., The Mobile Phone - An Artefact of Popular Culture and a Tool of the Public Sphere, Convergence br. 3, SAGE Publication 2002, str. 15-26.

9 Informatičkim riječnikom SMS se definira kao usluga prijenosa tekstualnih poruka putem mobilnih uređaja, faks uređaja i interneta. Poruke ne mogu biti duže od 160 znakova. Kada korisnik pošalje poruku prihvaća je SMS centar i prosljeđuje je na odredišni mobilni uređaj. Da bi pronašao gdje se u tom trenutku nalazi prijemni mobilni uređaj, SMS centar šalje SMS zahtjev registru kućnih lokacija koji treba pronaći klijenta. Kada je primio zahtjev registar kućnih lokacija odgovara SMS centru, dojavljujući mu status pokretnog preplatnika, koji može biti aktivan ili ne aktivan (Panian, 2007,182). 
nadmašuje $e-$ mail, pozive i tradicionalnu fiksnu telefonsku liniju, zbog toga što je jeftina, osobna, te predstavlja izravnu vezu između dvije osobe. Tekstualne poruke su asinkrone, odnosno ne zahtijevaju izravnu pažnju primaoca poruke, pa možemo reći kako su relativno nenametljive. Što je uzrok tome da se poruke sve više primaju i šalju za vrijeme nastave, školskog sata, sastanaka i čak duboko u noć? ${ }^{10}$ Danas je pisanje teskstualnih poruka postao globalni fenomen, koji se neviđenom brzinom raširio među mladima, oni su ga dobro usvojili i prihvatili, da je čak nekima postao primarnom formom komunikacije. Prema procjenama u svijetu se dnevno pošalje i primi oko četiri milijarde SMSova čime ovo postaje najmasovnija usluga telekomunikacijskih kompanija. ${ }^{11}$ Naglašava se kako je pisanje poruka koristan način ostajanja u vezi s određenim društvenim obvezama, bez trošenja vremena i energije na susrete. ${ }^{12} \mathrm{Na}$ tragu pretpostavke o SMS-u kao primarnom obliku komunikacije, upitali smo ispitanike/ce da izraze svoj stupanj slaganja s tvrdnjom: „Općenito se više koristim SMS-ovima nego pozivima“".

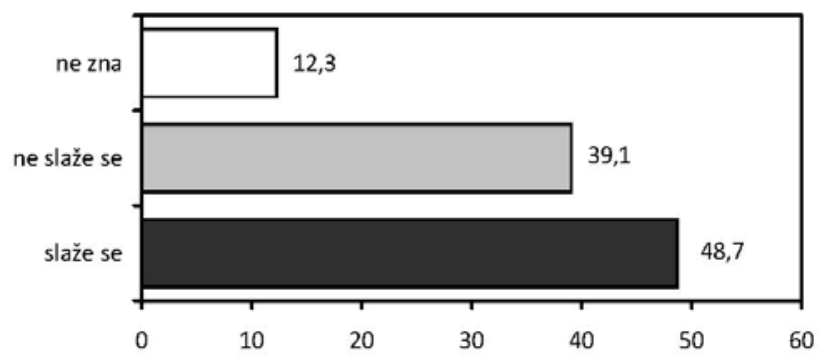

Grafikon 1 Grafički prikaz skale slaganja s tvrdnjom:

„Općenito se više koristim SMS-ovima nego pozivima“

Rezultati ukazuju na veći udio ispitanika/ca kojima je SMS komunikacija primaran oblik komunikacije, pa tako njih $48.7 \%$ više koriste SMS poruke od poziva. Slijedi 39.1\% ispitanika koji se nisu složili s datom tvrdnjom, te $12.3 \%$ koji ne znaju što prevladava u njihovoj komunikaciji.

Mnoge znanstvene rasprave vode se o tome koliko je dobra, odnosno loša SMS komunikacija za mlade, obzirom na njezin neosporan utjecaj na govorni i pisani diskurs, ali i kulturu uopće. Postavljaju se pitanja o gubitku socijalnih vještina, bespotrebnog

10 Ling R., The socio-linguistics of SMS: An analysis of SMS use by a random sample of Norwegians, in: Mobile communications: Renegotiation of the social sphere, eds. Ling R. and Pedersen P., London 2005, str. 335.

11 Balakrishnan V., Yeow P. H. P., Texting Satisfaction: Does Age and Gender Make a Difference?, International Journal of Computer Science and Security br. 1, Kuala Lumpur 2007, str. 85.

12 Campbell M. A., The impact of the mobile phone on young people's social life, in: Social Change in the 21st Century Conference, Brisbane 2005, str. 4. 
trošenja novca, problema elektroničkog zlostavljanja, a upitna je i kvaliteta jezičnog izražavanja mladih koja vodi prema redukciji socijalnih vještina, verbalnog i neverbalnog izražavanja. Istovremeno, određeni broj zagovornika SMS-a smatra kako ovaj oblik upotpunjava jezično znanje, iz razloga što pronalazi brojne kreativne načine izražavanja i sporazumjevanja, korištenja i modificiranja jezika na različite načine. Šunić13 navodi kako mnogi stručnjaci socijalne vještine opisuju kao sposobnosti nužne za uspješno međuljudsko funkcioniranje, tj. snalaženje $u$ ljudskom društvu. Socijalne vještine uključuju verbalna i neverbalna ponašanja, koje, kao svojevrsne sposobnosti, omogućuju osobi da na zadovoljavajući način ispuni društvena očekivanja. Tri su elementa socijalne interakcije u procjeni socijalnih vještina: društveni input - primjećivanje i razumijevanje tuđega govora, govora tijela, kontakta očima i kulturom određenog načina ponašanja; unutarnje obrađivanje podataka - odgonetavanje onoga što nam drugi žele reći, kao i prepoznavanje i izlaženje na kraj s vlastitim emocijama i reakcijama; društveni output - kako osoba komunicira s drugima i reagira govorom, izrazom lica i govorom tijela. Ako mladi primarno komuniciraju putem SMS-a izostaje društveni input, unutarnje obrađivanje podataka i društveni output. Kada komuniciramo SMS-om, tada teže shvaćamo ili čak možemo pogrešno protumačiti riječi, raspoloženje ili namjere druge osobe. To može kod pojedinca stvoriti pogrešne zaključke i neprikladne reakcije.

Ivas i Žaja ${ }^{14}$ u kontekstu nedostatka jezičnih komponenti govorne komunikacije prilikom komuniciranja SMS-om izlažu model prevladavanja nedostataka. U računalnom komuniciranju postalo je uobičajeno tekstualni sloj poruke oprirođivati dodatnim slikovnim znakovima koji u pisanje unose elemente govorne situacije. Budući da se tvore uz pomoć raspoloživih znakova na tipkovnici i javljaju uz tekst koji pretežno označava verbalni sloj govora, nazivaju ih uz-tekstualnim znakovima. Ističu se tri vrste takvih znakova:

1. Radnje - izražavaju neki tjelesni pokret ili čin koji pisac poruke smatra važnim sastavnim dijelom situacije koju primatelj treba zamisliti da bi razumio poruku. To se može učiniti tako da se naziv radnje upiše između dviju zvjezdica, npr. *zagrljaj*, *kihanje*, *osmijeh*, *plač*, *kimanje*, *zijevanje*, itd. Osim nazivom, radnja može biti naznačena onomatopejom ili kvazionomatopejom. Kvazionomatopeja podsjeća na onomatopeju, ali nosi neonomatopejski sadržaj. Naime, taj sadržaj

13 Šunić N., Komunikacija mladih putem SMS-a, Zdrav život br. 74-75, Zagreb 2009.

14 Ivas I. i Žaja L., Znakovi usmene komunikacije u pisanoj komunikaciji na IRC-u i ICQ-u, Medijska istraživanja br. 1, Zagreb 2003, str. 78-80. 
nije negovorni zvuk, niti se preko sinestetskih veza označuju vizualne, olfaktivne, taktilne ili proprioceptivne senzacije, nego je to skraćeni oblik naziva neke radnje ( $s a g=$ saginjanje, $\check{z} v a k$ = žvakanje). Sintaktički i grafički izdvojen opis relevantnog dijela situacije, koncentriran u nazivu (imenici), inovacija je računalskog komuniciranja. ${ }^{15}$

2. Grafičko označavanje govorne izvedbe - kao što su podebljavanje, podcrtavanje, uskličnici, upitnici i ostali interpunkcijski znakovi, velika slova i iterativno pisanje slova i drugih znakova inače služe za približno označavanje organizacije iskaza, a preko nje sintaktičke i obavijesne strukture iskaza, to jest, naglašavanje određenih riječi, te za izražavanje "tona", to jest načina na koji je tekst izgovoren ili bi bio izgovoren (primjerice vikanje se označava tako da se tekst ispiše velikim slovima; intenzitet emocije označava se uskličnicima i upitnicima; emfatični izgovor označava se ponavljanjem slova). ${ }^{16}$

3. Emotikoni, smajlići (smješci) - su slikovni izrazi emocija, raspoloženja i stavova (u pravilu shematizirano oslikavajući odgovarajući izraz lica) te radnji, situacija, bića i predmeta. Naziv emotikon (engl. emoticon) nastao je spajanjem engleskih riječi emotion (emocija) i icon (slika). Možda bi, radi preciznijeg razgraničenja, trebalo emotikonima zvati sve te znakove u širem smislu, a smajlićima samo one emotikone koji emocionalnost pokazuju slikom lica, a još uže samo onih nasmiješenih. Nastali su prenamjenom grafičkih tekstualnih oznaka, slova, brojki, interpunkcijskih znakova i matematičkih simbola, tako da su te oznake u raznim kombinacijama poslužile kao gradivo za stvaranje shematiziranih slika, kao u sljedećih nekoliko osnovnih i najčešćih smajlića: :-) :* ;) :-(..$^{17}$ Emotikoni su reprezentacija govora tijela, koja izaostaje u slučaju komunikacije koja nije licem u lice. Oni mijenjaju značenje teksta isto kao što i govor tijela može promjeniti značenje verbalne komunikacije u govornom diskursu. Stručnjaci emotikone nazivaju „hijeroglifima 21. stoljeća“. Gordon ${ }^{18}$ također ističe slično, odnosno tekstalne poruke postale su jedinstveni kodirani jezik. Složena subkultura kodova i domišljatih značenja razvila se korištenjem kombinacija skraćenica ${ }^{19}$, fonetike i emotikonsa.

15 Ibid., str. 80-81.

16 Ibid., str. 81.

17 Ibid., str. 82-83.

18 Gordon J., op. cit.

19 Kao na primjer što su: AFAIK as far as I know (koliko ja znam); BTW by the way (usupt rečeno); GAL get a life (nađi si život); IMO in my opinion (prema mom mišljenju); LOL laughing out loud (smijem se naglas); THX thanks (hvala). I neke naše popularne skraćenice, kao što su: SAJB sorry ako je bilo; 
TINA BOŽIĆ i RENATA RELJA

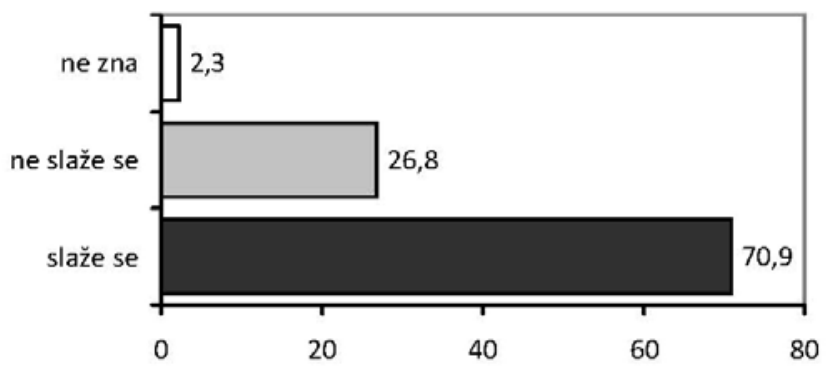

Grafikon 2 Grafički prikaz skale slaganja s tvrdnjom: „Često u SMS porukama koristim emotikone“

Nadalje, u kontekstu iznešenog zanimalo nas je u kolikoj mjeri ispitanici/e u tekstualnoj komunikaciji koriste emotikone.

Iz prethodnog grafičkog prikaza, vidljivo je da su i naši ispitanici/e prihvatili i usvojili korištenje emotikona kao načina izražavanja vizualnih gesta prilikom pisanja SMS poruka. Velika većina, čak 70.9\% (122 srednjoškolca i 92 studenta) u SMS porukama koristi se emotikonima, tek $26.8 \%$ (28 srednjoškolca i 53 studenta) izjasnilo se o nekorištenju, a zanemarivih $2.3 \%$ ( 2 srednjoškolca i 5 studenata) ne zna, tj. ne može procijeniti. Temeljem hi-kvadrat testa $\left(\chi^{2}=13.195, \mathrm{df}=2, \mathrm{AS}=0.001\right)$ ustanovljeno je kako školska sprema utječe na korištenje emotikona u SMS porukama, odnosno mlađa populacija (srednjoškolci) više i češće se koriste emotikonima od one studentske. Također hi-kvadrat ukazuje $\left(\chi^{2}=54.139, \mathrm{df}=2, \mathrm{AS}=0.000\right.$, koja je manja od 0.5) na povezanost spola i korištenja emotikona. Tako su žene u odnosu na muškarce sklonije korištenju emotikona u SMS porukama. Od 70.9\% njih koji su izjavili da se koriste emotikonima, takav odgovor dalo je 152 žene i trostruko manje muškaraca (62). Od 26.8\% koji se ne slažu s datom tvrdnjom (61 je muškarac, a trostruko manje žena 20).

Tekstualne poruke također služe zbližavanju grupe vršnjaka kroz razvitak zajedničke povijesti. ${ }^{20}$ Izazovi kao što su mali ekrani, limitirani broj znakova po poruci, SMS komunikacija opravdava korištenjem sintatičkih i leksičkih kratkih formi, skraćenica i akronima, čuvajući time slobodni prostor za pisanje poruke, ili pak pošteđuje osobu tipkanja. Takva metoda produkcije teksta također štedi vrijeme, novac i napor. Korištenje skraćenica i akronima ispunjava funkciju kolektivnog identiteta iz razloga što podrazumijeva specifično znanje koje omogućava razumijevanje tog jezika i naravno njegovo korištenje. Adaptirano

AMR ako me razumiješ (http://www.mob385.com/gsm/kratice.shtml, 06.08. 2010)

20 Ling prema Rafi M. S., op. cit., str. 395. 
korištenje personaliziranog jezika indikator je pripadnosti grupi i komponenta je grupnog identiteta. Taj specifični jezik predstavlja odmak od standardnog jezika, pa se SMS komunikacija označava kao „tajni kod“ mladih ili pak kao velika SMS akcija protiv dugačkih rečenica. ${ }^{21}$ Kompleksnost razmatranja SMS komunikacije, upućuje i na mogućnost ili nemogućnost ostvarivanja ,intimne komunikacije“, odnosno održavanja intimnosti, dubine odnosa i bliskosti sudionika komunikacije. Primjerice, otkazivanje poslovnih susreta, odnosno prekid ljubavne veze putem SMS-a može se „tretirati“ kao neprikladan. Sindik i Reicher ${ }^{22}$ kompariraju pisanje pisma i elektroničku poštu. Tako je pisanje pisama oblik intimne, bliske komunikacije, dok pisanje elektroničke poruke označava puku razmjenu informacija. Mnogi vjeruju da su bliski i topli ljudski odnosi koji su se razvijali putem pisma, „naprasno“ uništeni elektroničkom komunikacijom, pa je tako mobitel postao idealno sredstvo za izbjegavanje susreta licem u lice. Danas se poruke šalju roditeljima, kolegama, profesorima, razrednicima. Čak i kad se dvoje mladih rastaju, nerijetko to jedan drugome priopćavaju upravo SMS porukom. Kako navodi Mandarić ${ }^{23}$ to je bijeg od suočavanja sa stvarnim svijetom. Pisanje poruka također služi izbjegavanju neugodne tišine i stvaranja konverzacije. One omogućavaju stidljivim ili rezerviranim mladima komuniciranje bez posramljujućih emocija. Neki se sociolozi slažu kako će mladima koji radije izabiru pisati poruke nego razgovarati o neugodnim i emocionalno teškim situacijama, to utjecati na sposobnost međusobne interakcije. ${ }^{24}$ Upitali smo ispitanike/ce o njihovom iskustvu korištenja SMS poruka u svrhu izbjegavanja neugodnih situacija ili izražavanja nečega što bi moglo biti stresno kada bi se odvijalo licem u lice.

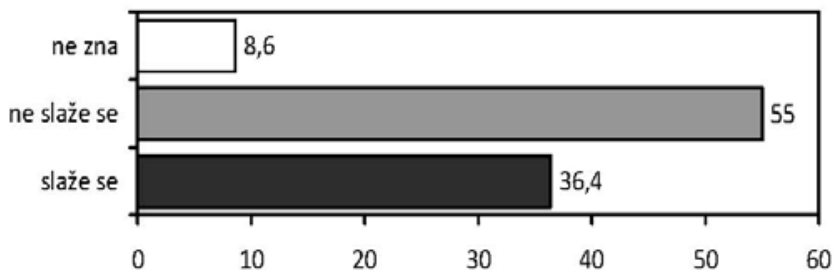

Grafikon 3 Grafički prikaz skale slaganja s tvrdnjom: „Priopćio/la sam SMS-om stvari koje nisam mogao/la izreći licem u lice (raskid veze, prekid suradnje)“

21 Doring prema ibid., str. 395.

22 Sindik J. i Reicher K., Internet kao sredstvo za ostvarivanje ,intimnije“ komunikacije, Metodički ogledi br. 2, Zagreb 2008, str. 85.

23 Mandarić V. B., Mladi integrirani i (li) marginalizirani, Zagreb 2009, str. 122.

24 Srivastava prema Campbell M. A., op. cit., str. 4. 
Više od polovice ispitanika/ca nije se složilo s danom tvrdnjom (55\%), a njih 36.4\% putem SMS-a priopćilo je stvari koje nije moglo izreći licem u lice. Sukladno ovom pitanju upitali smo mlade za njihov stupanj slaganja s tvrdnjom Dogovorio/la sam prvi spoj s nekim preko SMS poruka, kao specifičnom situacijom koja kod većine mladih izaziva izvjesnu dozu stresa i nelagode. Potvrdan odgovor dala je većina ispitanika/ca njih 45.4\%, kako se ne slaže s datom tvrdnjom odgovorilo je $39.7 \%$, a njih $14.9 \%$ izjasnilo se kako ne zna. Moguće je zaključiti da se ispitanici/ ce u gotovo podjednakom omjeru koriste, odnosno ne koriste SMS porukama prilikom priopćavanja relativno stresnih ili neugodnih stvari.

\section{Redefiniranje mjesta $i$ vremena}

Za Castellsa $^{25}$ mobilna komunikacija omogućava krajnji oblik umreženog društva u kojem vlada „vječno vrijeme“ i „beskonačni prostor“. To je mreža proširena nad bilo kojom individualnom lokacijom i vremenskom zonom; kreirajući svoje vrijeme-prostor koje se proširuje na sva područja kroz sva

vremena.

Globalizirajući porast korištenja bežičnih medija komunikacije omogućio je razvoj mnogobrojnih različitih komunikacijskih praksi koje su prostorno razdvojene, te se predstavljaju kao izvanprostorne i vanvremenske aktivnosti. Komunikacijska tehnologija sve se više odvaja od konkretnog prostora, u kojem se pojedinac koji komunicira trenutno nalazi (u uredu, stanu, na ulici, Internet Caffeu), stoga je legitimno utvrditi da se netko ne nalazi negdje, jer je nemoguće provjeriti je li netko stvarno negdje. Ovdje, sada, tu sam, nisam tu su društveno proizvedena kontekstualna mjesta postojanja s obzirom na trenutne aspiracije, potrebe i ideje korisnika/ce nekog mobilnog uređaja. ${ }^{26}$

Objašnjavajući naznačenu redefiniciju mjesta i vremena Caronia $^{27}$ govori o novim značenjima produciranim korištenjem tehnologija, kao što su značenja „ne-mjesta“ i „,ne-vremena“. Nigdje-mjesta su mjesta prelaženja lišena bilo kakvih kulturalnih ili individualnih značenja, mjesta koja postoje samo da bi ih se prešlo i kako bi došli na mjesto većeg značenja. Ne-vrijeme možemo definirati kao stanje mirovanja (stand by) koje ne može

25 Castells M., Fernandez-Ardevol M., Qiu J. L. i Sey A., Mobile communication and society: a global perspective, Cambridge 2007.

26 Čaldarović O. i Šarinić J., Suvremena komunikacijska tehnologija i urbana sredina - prostor, mjesta, vrijeme, Socijalna ekologija br. 4, Zagreb 2008, str. 332.

27 Caronia L., Mobile culture: An etnography of cellulare phone uses in teenagers everday life, Convergence br. 3, SAGE Publication 2005, str. 97. 
biti definirano u odnosu na neku određenu aktivnost, to je vrijeme u kojem akter jednostavno „čeka nekoga tko dolazi“ ili „čeka da se nešto dogodi“. Fascinantno je kako tehnologija daje značenja ovim beznačajnim vremenima i prostorima. Veliki postotak poziva koji mladi dobivaju ili upućuju, dolaze iz tih nigdje-mjesta u tom ne-vremenu. Čekajući autobus, hodajući nekamo, na ulici ili na bilo kojem drugom mjestu koje se ne može precizno definirati zbog njegove neutralne prirode. Tako primjerice Green ${ }^{28}$ mobilni telefon naziva „Lazarus uređajem“ koji može oživjeti „mrtve trenutke“ (dead moments) misleći pri tome kako mobilna komunikacija ispunjava „prazno vrijeme“.

Mobilni telefon se s teorijske perspektive može sagledati kao tehnologija za podešavanje vremena i prostora, $s$ mogućnošću mjenjanja društvenih obrazaca i organizacije zajednice. Na isti način kao i druge transportne i komunikacijske tehnologije, kao što su - automobil, fiksna telefonska linija, televizija, internet - ima potencijal transformacije ljudskih obrazaca mobilnosti, aktivnosti i kontakta u vremenu i prostoru. ${ }^{29}$ Jedna od najčešćih funkcija korištenja mobitela među mladima je i izmjenjivanje i re-planiranje dogovora, što je poznato kao ,hiperkoordinacija“ ili kao „približni-dogovori“ (approxi-meetings). Mladi jednostavno gube pojam vremena i prostora, vodeći se mišlju kako imajući mobitel možeš kasniti, ne doći na vrijeme ili u hodu promjeniti dogovore. ${ }^{30}$ Također i Caronia ${ }^{31}$ ističe takvo tipično ponašanje mladih, $u$ kojem oni dogovaraju susrete i koordiniraju zajedničke aktivnosti s nekoliko brzih i kratkih poziva. Oni susrete ugovaraju korak po korak, trenutak za trenutkom, kao da idu prema točki susreta i vremenu koje se treba specificirati. Mobiteli (koji prema nepisanim društvenim normama uvijek moraju biti uključeni) - promjenili su prirodu sastajanja mladih. To više nije konkretna akcija u određenoj točki vremena, već je zajednički postignuti proces. Tradicionalne koordinate mjesta i vremena, sada se pomiču, one su fluidne, te se izmjenjuju iz trenutka u trenutak.

28 Green prema Arminen I., Review Essay Mobile Communication Society?, Acta Sociologica br. 4, Nordic Sociological Association and SAGE 2007, str. 433.

29 Thulin E. i Vilhelmson B., Mobile everywhere - Youth, the mobile phone, and changes in everyday practice, Young: Nordic Journal of Youth Research br. 3, Copenhagen 2007, str. 238.

30 Tutt D., Mobile Performances of a Teenager: A study of Situated Mobile Phone Activity in the Living Room, Convergence: The International Journal of Research into New Media Technologies, br. 2, SAGE Publication 2005, str. 60.

31 Caronia L., op. cit., str. 100. 
Ritual „sastanka“ se promjenio, tradicionalno su postojala neka mjesta u urbanoj sredini koja su definirala sastajanja mladih, kao što su kafići, parkovi, prostor pored zgrade i slično. Zbog mobitela sve je manje specifičnih urbanih mjesta, oni su izgubili svoju ritualnu funkciju, te sada svako mjesto više ili manje može biti mjesto sastanka. Ista stvar, naglašava Caronia ${ }^{32}$, dogodila se i s vremenom koje je također izgubilo svoju ritualnu funkciju. Sada mladi više ne rane niti kasne na susrete s prijateljima. Doći na vrijeme postalo je zajednička i progresivna konstrukcija postignuta od strane članova grupe.

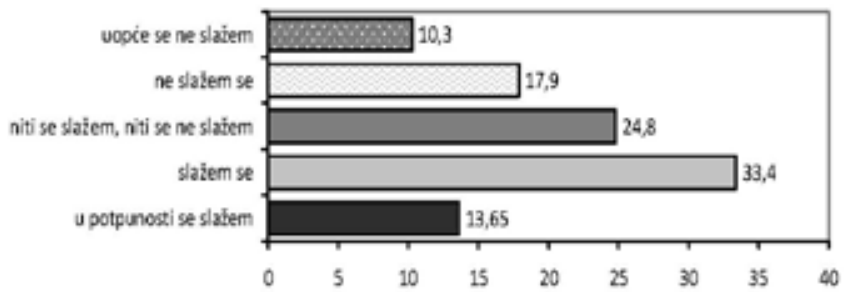

Grafikon 4 Grafički prikaz skale slaganja s tvrdnjom: „Mobitel mi omogućuje lakše organizirati svoje vrijeme“"

Ispitanici su nadalje izrazili stupanj slaganja s tvrdnjom: Mobitel mi omogućuje lakše organizirati svoje vrijeme. Kako je vidljivo iz grafičkog prikaza, većini ispitanika mobitel zaista omogućava lakše organiziranje vremena (47\%), to ne vrijedi za njih $28.2 \%$, dok se $24.8 \%$ ispitanika s time niti slaže, niti ne slaže.

\section{Konverzacijski prostor ${ }^{33}$}

Palent ${ }^{34}$ uočava kako se korisnici prilikom razgovora mobitelom, simultano nalaze u dva prostora: u prostoru u kojem se fizički nalaze i u prostoru konverzacije. Također napominje, prilikom dolaska poziva, korisnici svjesno ili nesvjesno odlučuju, koje će njihovo lice prednjačiti: ono koje je sukladno fizičkoj okolini ili ono svojstveno konverzacijskom prostoru. Prostor

\section{Ibid., str. 119.}

33 Afrić $(1999,181)$ ovaj konverzacijski prostor naziva kibernetskim prostorom, a objašnjava kako je to konceptualni prostor koji nastaje upotrebom suvremenih tehnologija, u kojem se, kada ljudi koriste posredovanu tehnologiju, manifestiraju riječi, ljudske relacije, podaci, dobrobit i moć. Pojam kibernetski prostor nastao je u znanstvenoj fantastici Williama Gibsona, a pjesnik John Perry Barlow opisao ga je simbolično i jednostavno kao ono mjesto, gdje smo kada govorimo telefonom. Taj kibernetski prostor nije fizička lokacija, to je stanje uma, mjesto istovremeno realno i artificijelno. On je svijet ljudskih svijetova on je n-dimenzionalan prostor ili prostor svih ljudskih prostora (Afrić, 1999, 191).

34 Prema Truch A., Exploring the implications for social identify of the new sociology of the mobile phone, The global and local in Mobile Communication: Places, Images, people, and connections, Budimpešta 2004, str. 4. 
koji prednjači odnosi se na Goffmanov koncept ,prednjeg plana“, odnosno „stražnjeg plana“. Ukoliko fizički prostor postane „stražnjim planom“, a konverzacijski „prednjim“, možemo reći da je pojedinac „odsutno prisutan“, fizički je tu, ali apsorbiran od strane tehnološkog medija nekog drugog prostora. Pojedinci sada imaju složenu situaciju koja od njih zahtjeva djelovanje u dva distancirana prostora: prostor fizičkog prisustva $\mathrm{i}$,telefonski prostor“ (phonespace) u kojem se odvija mobilna komunikacija.

Biti istovremeno na dva različita mjesta vrlo je problematično. Sudionici razgovora su na mobitelu, njihov sastanak je realan, ali ne postoji mjesto ili lokacija njihovog sastanka, telefonski razgovor se događa u prostoru (space), ali ne i na nekom mjestu (place). Taj međuprostor je apstraktna logička posljedica koprisutnosti (copresence). Taj prostor nema dimenzije i sudionici ne zauzimaju realne pozicije unutar njega, što rezultira istovremenim postojanjem unutar dva različita prostora. To također možemo prikazati i još složenijim, te nadodati kako u stvari postoje tri prostora/mjesta, ona u kojima svaki od sudionika fizički jest i konverzacijski prostor. ${ }^{35}$ Tehnologija je omogućila ulazak u nematerijalni životni prostor, izmještanjem materijalnog tijela iz područja neposrednog životnog prostora. ${ }^{36}$

Brown i Perry ${ }^{37}$ pokušali su pobliže objasniti koje su općenite razlike između mjesta i prostora (place/space): „Nazivati nešto mjestom, znači usredotočiti se na smještaj, utjelovljenje, osobnu, lokalnu, ljudsku prirodu. Nazivati nešto prostorom jest usredotočiti se na apstraktne, objektivne, globalne, općenite, neljudske značajke. Prostor je ,apstraktan i distribuiran“, a mjesto je „lokalno i kontigentno.“

Neizvjesnost u pogledu apstraktnih uloga vezanih za prostor može izazvati veliki stres kod korisnika mobitela - s konstantnom dostupnošću za mobilnu komunikaciju, nemoguće je pretpostaviti koja će od uloga biti manifestirana. Oni moraju biti pripremljeni za svaku od uloga cijelo vrijeme. Ovo je jasno demonstrirao Plant ${ }^{38}$ : ,, Postoji nešto vrlo komično u tome kako korisnici mobitela pokušavaju upravljati pozivom čiji su sadržaj i emocionalni iskazi nepoznati osobama oko njih: konverzacija s ljubavnikom u vlaku ili pak s ljutitim šefom u baru. Neke

35 Rettie M. R., Presence and Embodiment in Mobile Phone Communicatin, PsychNology Journal br. 1, 2005, str. 20.

36 Afrić V., Kibernetski prostor i virtualna realnost kao društvena upotreba informacijskih i komunikacijskih tehnologija, Revija za sociologiju br. 3-4, Zagreb 1999, str. 182.

37 Prema Rettie M. R., op. cit., str. 19.

38 Prema Truch A., op. cit., str. 4. 
konverzacije mogu potaknuti emocionalne i tjelesne odgovore koji mogu biti vrlo nekompatibilni s percepcijom njihove fizičke prisutnosti. Korisnici se često čine kao da ne znaju što će sa sobom, kako rekonfigurirati ton glasa i položaj tijela koji bi normalno pratio takvu konverzaciju“. Ovakvo neizvjesno ponašanje može također izazvati stres i kod osoba koje se nalaze oko njih. Oni mogu promijeniti svoje mišljenje o osobi kada vide ponašanje koje je u raskoraku s prvotnom percepcijom individue. Također mogu smatrati da je neki od tih identiteta „lažan“. Ovo objašnjava iziritiranost ili neugodu koju drugi osjećaju gledajući neku osobu kako na nedoličan način priča na mobitel.

Monk i dr. ${ }^{39}$ postavljaju pitanje zašto bi komunikacija koja se odvija putem mobitela (a znači prisutnost jedne osobe na javnom prostoru i druge koja je odsutna) bila neugodnija ili neprijatnija od komunikacije koja se odvija između dvije osobe istovremeno prisutne na konkretnom javnom prostoru. Navode tri razloga kao objašnjenja za negativnu reakciju i stav prema mobilnoj komunikaciji: 1. drugačija konverzacija - nešto je drugačije u načinu na koji ljudi pričaju kad koriste mobitel. Često je slučaj da ljudi pričaju mnogo glasnije ili govore o nekim privatnim stvarima. Kada su obje osobe prisutne, razumljivo je kako će poteškoće u razgovoru zbog buke u okolini, predstavljati problem i jednoj i drugoj osobi. Ljudi automatski prilagođavaju svoj sluh i ton glasa okolinoj buci i smetnjama čime se smanjuje antisocijalno ponašanje. Referirajući se na Goffmana (1971), autori navode kako se fizičkim odsustvom primarne publike (osobe koja je s druge strane telefonske linije), događa slučaj izravnog preusmjeravanja konverzacije prema sekundarnoj publici (osobe koje prisluškuju razgovor), čime govornik ulazi u prvi plan, te je pažnja usmjerena na njega; 2. potreba za slušanjem - autori ovaj razlog objašnjavaju teorijom jezika. Modeli razumjevanja jezika kao kolaborativne aktivnosti naglašavaju kako konverzacija ovisi o razumijevanju, odnosno, naša konverzacijska obveza je razumjeti drugoga, te biti razumljiv drugome. Ova potreba za razumjevanjem automatski se javlja kada čujemo samo jednu stranu konverzacije. Primjerice, ako čujemo pitanje, direktno imamo potrebu čuti i odgovor na to; 3. općenito negativni stav

\section{prema mobilnim telefonima.}

\section{Javno vs. privatno}

Danas je rasprostranjeno mišljenje da nove tehnologije, kao što su mobilni telefoni, brišu granice između privatnog i javnog života pojedinca. Tradicionalne definicije i ideje o tome što je

39 Monk A., Fellas E. i Ley E., Hearing only one side of normal and mobile phone conversations, Behaviour \& Information Technology br. 5, Taylor \& Francis 2004, str. 301-305. 
javno a što privatno, mijenjaju se ulaskom tehnologije u svakodnevne živote ljudi. Mobitel je „,nediskretna“ tehnologija, koja uvodi ono osobno u javni svijet, te time vjerno prikazuje rastući kulturalni trend svih novih komunikacijskih medija. Naš je društveni život organiziran i vremenski strukturiran tako da dok u nekim vremenskim razdobljima moramo biti drugima dostupni, postoje i razdoblja u kojima je opravdano biti nedostupan. Zato je vrijeme u tolikoj mjeri središnje prilikom definiranja i reguliranja društvenih angažmana, pripadnosti i dostupnosti. Mobilni telefon znači trajnu dostupnost, on briše granice između privatnog i poslovnog života. Vrijedno međuvrijeme koje se prije provodilo u sređivanju misli i odmoru, sada je sve više narušeno stalnom zvonjavom i paničnim pokušajima da se $u$ ,posljedni tren“ dogovore neriješene pojedinosti. ${ }^{40} \mathrm{U}$ kontesktu psihološkog osjećaja konstantne dostupnosti koja je posljedica posjedovanja mobilnog telefona, upitali smo ispitanike/ce o njihovom stupnju slaganja s tvrdnjom: Imam osjećaj da sam na raspolaganju uvijek $i$ svakome. Većina mladih s time se slaže (46.7\%), i u potpunosti se slaže (15.2\%). Mladih koji nemaju takav osjećaj je $10.9 \%$, te $4.3 \%$ onih koji se uopće ne slažu, dok je $30.1 \%$ ispitanika koji su izjavili kako se s ovim niti slaže, niti ne slaže.

Zerubave ${ }^{41}$ predlaže da se na stupanj društvene dostupnosti pojedinca gleda kao na odnos između dvije hipotetičke tvorevine - privatnog vremena i javnog vremena - od kojih niti jedan ne postoji u svojem čistom obliku. Mnogi pripadnici našeg društva smatraju noć relativno sociofugalnim tj. privatnim vremenskim razdobljem, dok se dan općenito smatra javnim i sociopetalnim. No ovdje je važno napomenuti paradoksalnu situaciju. Upravo zato što je društvena interakcija noću neuobičajenija nego ona danju, ta je noćna interakcija često osobito intimna. Također se smatra da su ljudi obično prijateljski raspoloženi i spremniji pomoći drugima noću nego danju. Iz razloga što se noć smatra sociofugalnim vremenskim razdobljem, interpersonalne barijere se lakše uklanjaju noću nego danju. Sama definicija vremenskih granica koje razdvajaju privatna vremenska razdoblja od onih javnih, varira od kulture do kulture.

Na tvrdnju Ne isključujem mobitel niti kad spavam, većina ispitanika/ca daje potvrdan odgovor $-18.2 \%$ se u potpunosti slaže s tvrdnjom, njih čak 36.4\% se slaže, onih koji iskazuju negativan stav prema tvrdnji, dakle noću isključuju mobitel je $15.2 \%$, a njih $30.1 \%$ izjavilo je kako se niti slaže niti ne slaže. Slično

40 Giddens A., Sociologija, Zagreb 2007, str. 469.

41 Zerubavel E., Privatno i javno vrijeme, III Program hrvatskog radija br. 42, Zagreb 1993, str. 16. 
pokazuju i rezultati dobiveni odgovorima na tvrdnju Dok spavam mobitel je uvijek pored mene. Mobitel je zaista uz čak 74.5\% ispitanika i dok spavaju, za razliku od svega $13.3 \%$ ispitanika koji ne robuju ovoj navici, te njih $12.3 \%$ koji se niti slažu niti ne slažu. Odgovori ukazuju na naviku držanja uključenog mobitela i unutar najprijatnijeg vremena, odnosno u vrijeme kada osoba spava. Indikativno je i za ovaj kontekst spomenuti već prije iznesene rezultate o navici mladih slanja SMS poruka prijateljima ili mladiću/djevojci duboko u noć kada legnu u krevet spavati. Njih 23.9\% izjavilo je kako se slaže s navedenom tvrdnjom, u potpunosti se slaže $13.9 \%$, a $21.9 \%$ niti se slaže niti se ne slaže. S druge strane njih 19.2\% uopće se ne slaže s navedenom tvrdnjom, a $20.9 \%$ se ne slaže. Takve namjerne telefonske pozive ili SMS poruke u sitne sate, možemo protumačiti i kao izraz društvene bliskosti i prisnosti osoba koja se manifestira ovim oblikom komunikacije.

Društveno značenje telefoniranja, zvanja na fiksni kućni telefon iza 14 sati uvelike ovisi o tome događa li se to unutar kulturalnog konteksta u kojem je uobičajen dnevni odmor. ${ }^{42}$ No, ukoliko zovemo na osobni telefon, odnosno na mobitel, kao da ne postoje nikakva vremenska ograničenja ili pitanja pristojnosti i bontona. Također, biti društveno dostupan mobitelom, bitno se razlikuje od dostupnosti na izravan kontakt. Dok bi se u nekom vremenskom razdoblju poziv na mobitel/ fiksni telefon smatrao prikladnim, posjet bez najave bi mogao biti smetnja. Dati nečiji telefonski broj drugome, a posebice broj mobitela - što je mnogo osobnije, obzirom da se broj mobitela ne može pronaći u imeniku ili na informacijama - najznačajniji je čin ukazivanja na njegovu dostupnost. Taj čin ne samo da ima praktično značenje dostupnosti nekog telefonskog broja, nego simbolički uključuje druge u selektivan i isključiv krug.

Privatnost nije povrijeđena samo stalnom zvonjavom mobitela, nego i samom spoznajom da bi on mogao svakog trena zazvoniti. Od tuda i praksa isključivanja mobitela, namjerna nejavljanja, stavljanja na bešumne opcije ili vibrirajuće kako bi povećali nedostupnost. No čak i takav čin mora odgovarati određenoj vremenskoj definiciji ako želimo da bude društveno prihvatljiv. Općenito govoreći, imamo više prava odijeliti se od ostatka svijeta u vremenskim razdobljima koja se i onako smatraju sociofugalnim. Stoga nas više vrijeđa i frustrira ako nam je netko nedostupan danju, nego noću. ${ }^{43}$ Drugi ekstrem je namjerno uzdržavanje od toga da se isključi mobitel. Stalna dostupnost simbolički predstavlja osjećaj da se nalazimo u toku događanja. Često 
je prilično stresna i frustrirajuća situacija ukoliko nam mobitel ostane bez baterije, novaca, ukoliko ga izgubimo ili slično. Imamo osjećaj izoliranosti od drugih, nedostupnosti, često mislimo kako propuštamo ili ćemo pak propustiti nešto bitno, imamo osjećaj isključenosti (mobitel nam je isključen, pa smo i mi isključeni) iz važnih događanja. Na tragu ovog razmišljanja, zanimao nas je stupanj slaganja naših ispitanika/ca sa sljedećom tvrdnjom:

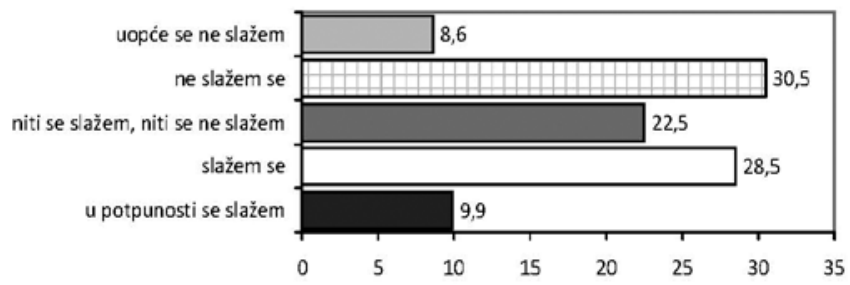

Grafikon 5. Grafički prikaz skale slaganja s tvrdnjom: „Suzdržavam se od isključivanja mobitela, kako ne bih propustio/la nešto bitno“.

Ispitanici/e u najvećem broju ne isključuju mobitel (39.1\%), dok je s druge strane onih koji to rade $38.4 \%$, dok jedna trećina pokazuje indiferentan stav prema datoj tvrdnji.

Goggin $^{44}$ navodi kako praksa uvijek uključenog mobitela dovodi do konflikta između javnog i privatnog života. Mobiteli kao da uzrokuju nejasnu sliku o tome što je privatni, a što poslovni svijet, te sve više pridonose povećavanju radnog opterećenja. Geser $^{45}$ ističe kako mobilna komunikacija općenito predstavlja smetnju, upravo iz razloga što mobitel može zazvoniti bilo kada i bilo gdje, u bilo kojoj nepredviđenoj situaciji, potičući primaoca poziva da odgovori na poziv, usmjeri svu svoju pažnju na to, bez obzira na okolnosti u kojima se nalazi. Taj pritisak na individuu u smislu mijenjanja uloga i preusmjeravanja pažnje može rezultirati povećanjem psihološkog stresa. Istovremeno osoba koja na javnom mjestu čuje privatni razgovor druge osobe to također može doživaljavati kao smetnju i kao nešto što joj je nametnuto bez njezine volje. Hawk i dr. ${ }^{46}$ ilustriraju tu situaciji na sljedeći način: „Osoba priča na mobitel postavljajući pitanje svom sugovorniku „Čuješ li me?“. S druge strane osoba koja se nalazi pored nje na javnom mjestu odgovara: „Da! Ja te čujem, čujem tvoju konverzaciju s drugom osobom, i čujem sebe kako sam uvučen u tvoje privatno područje konverzacije. Iako misliš

\footnotetext{
44 Prema McLeod E., The Use (and Disuse) of Mobile Phones by Baby Boomers, International Journal of Emerging Technologies and Society, br. 1, Hawthorn 2009, str. 28-38.

45 Prema ibid.

46 Hawk B., Rieder D. M. i Oviedo O., Small Tech: The Culture of Digital Tools, Minnesota 2008, str. 97.
} 
da nisam dio tvoje privatne konverzacije, ja čujem sve što govoriš.“ Kako Nedra Reynolds ${ }^{47}$ piše: „Slušateljima predstavlja smetnju čuti ,privatni““ telefonski razgovor, zbog toga što takva konverzacija ruši odnos između privatne i javne sfere - a to je ono što većina ljudi pokušava držati u distanci.“ Čuti privatnu konverzaciju u javnom prostoru narušava granicu između te dvije sfere. Bilo bi pogrešno pretpostaviti kako mobilni telefoni jednostavno unose ono privatno u javni prostor ili javnim čine svoj privatni prostor. Mobiteli su alati koji sukobavljaju distinkciju između javnog i privatnog, tehnologija općenito radi na način da kreira nešto što bi mogli nazvati zona javne intimnosti. Korisnici mobitela nisu u potpunosti u privatnoj sferi niti su u potpunosti u javnoj sferi, oni egzistiraju kao intimno javno tijelo.

\section{Bonton korištenja mobitela}

Neosporno je kako su mobiteli najčešće korišteni digitalni proizvod, a komunikacija putem mobitela je sveprožimajuća, te prema tome i neizbježan segment javnog prostora. U usporedbi s drugim komunikacijskim sredstvima koje se mogu primjetiti na javnom prostoru, mobiteli su relativno recentan fenomen, pa se prihvatljiva pravila njegova korištenja još evaluiraju. Stoga nije iznenađujuće što veliki broj ljudi smatra neugodnim javno korištenje mobitela, te se zbog toga i stvaraju mjere koje ograničavaju ljude $u$ korištenju mobitela $u$ određenim javnim prostorima. Brojne su ustanove i javni prostori koji na pisani ili slikovni način sugeriraju zabranu korištenja mobitela (npr. lječničke ordinacije, kazališta, škole, za vrijeme vožnje auta itd), neke su zemlje čak uvele i zabranu korištenja mobitela u javnom prijevozu kao što su vlakovi i autobusi ${ }^{48}$ Pojedinci koriste mobitel u javnim prostorima bez ustručavanja, kršenjem konvencija o diskretnosti i čednosti. Oni će raspravljati i razgovarati o privatnim i intimnim stvarima u javnosti, toliko dugo koliko oni hoće. Sam mobitel ima toliki status da zahtjeva, ali i prima direktnu pozornost, uznemiravajući što god da je korisnik prije toga radio. Postoji opasnost da mobitel uzme primat pred konverzacijom licem u lice. Jedan od paradoksa njegova korištenja jest i taj da osigurava komunikaciju između onih koji su udaljeni i distancirani, dok u isto vrijeme ometa razgovor onih koji se nalaze u konverzaciji licem u lice. ${ }^{49}$ Miliša $^{50}$ sukladno tome zamjećuje kako u današnjim „ponudama“ industrijske zabave mladi čovjek gubi potrebu za „živom“ komunikacijom. Umjesto razgovora, komunicira se putem interneta, e-mail-a,

47 Prema ibid., str. 96.

48 Monk A., op. cit., str. 301.

49 Gordon J., op. cit.

50 Miliša Z., Manipuliranje potrebama mladih, Zagreb 2006, str. 13. 
SMS poruka. Tako reklama za mobilnu mrežu TELE 2 reklamirajući svoju povoljnu opciju o 1000 minuta besplatnog razgovora mjesečno $\mathrm{s}$ tzv. superfrendom, naglašava mogućnost kako bi se superfrendovi mogli naći u situaciji da si nemaju što reći u živo. Nije potrebno objašnjavati koliko i kako je loša sugestija o mogućnosti nepostojanja ,žive“ komunikacije među „superfrendovima“.

Razgovor licem u lice izumire zbog mobitela, a osnovna pristojnost nestaje zbog nevažnog poziva na mobitel ili tek dobivene SMS poruke. Zbog mobitela maniri su gori nego ikada, a oni koji neprestano rabe mobitel pokazali su se kao najnepristojniji. Veliki broj pojedinaca priznaje kako će se bez ustručavanja javiti na mobitel bez obzira na to jesu li u društvu, na blagajni trgovine, jedu li u restoranu ili su u knjižnici. Ling ${ }^{51}$ sukladno tome navodi da je korištenje mobilnog uređaja u različitim situacijama postalo dio definiranja društvenog ponašanja kao prikladnog odnosno neprikladnog. Obzirom na njih mi promišljamo o tome kako konstruiramo našu društvenu stvarnost. Njihovo korištenje zahtjeva reevaluaciju onoga što uzimamo zdravo za gotovo u svakodnevnom životu. Razvoj tehnologije znači razgovor na nov način, na novim mjestima i novim vremenima, sve to zahtjeva i nova pravila pristojnog i prikladnog ponašanja. Sukladno novoj kulturi komuniciranja koju pred nas stavlja uporaba mobilnih telefona, zanimalo nas je kako se ponašaju naši ispitanici/e u konkretnim situacijama i javnim prostorima koji po svojoj prirodi zahtjevaju prikladno ponašanje.

\begin{tabular}{|l|c|c|c|c|c|c|}
\hline \multirow{2}{*}{$\begin{array}{l}\text { PROSTORI I } \\
\text { SITUACIJE }\end{array}$} & nikada & rijetko & ponekad & često & uvijek & b.o. \\
\cline { 2 - 7 } & $\%$ & $\%$ & $\%$ & $\%$ & $\%$ & $\%$ \\
\hline u kazalištu & 4 & 1.7 & 5 & 8.6 & 77.5 & 3.3 \\
\hline u kinu & 6.3 & 5.3 & 8.6 & 15.6 & 64.2 & $/$ \\
\hline u školi/ fakultetu & 3 & 5.6 & 5.3 & 18.5 & 67.5 & $/$ \\
\hline u crkvi & 1.3 & 2.6 & 4 & 7.6 & 79.5 & 5 \\
\hline u avionu & 0.3 & $/$ & 0.7 & 1.7 & 71.9 & 25.5 \\
\hline $\begin{array}{l}\text { pri važnim sastancima, } \\
\text { predavanjima... }\end{array}$ & 2 & 1.7 & 3 & 9.9 & 82.1 & 1.3 \\
\hline na sprovodima & 1.7 & 1.7 & 2.6 & 4 & 89.1 & 1 \\
\hline $\begin{array}{l}\text { za vrijeme obroka s } \\
\text { drugima/u restoramu }\end{array}$ & 40.1 & 27.2 & 17.2 & 6.6 & 8.9 & $/$ \\
\hline u knjižnici & 20.5 & 12.3 & 17.5 & 9.3 & 39.4 & 1 \\
\hline u liečničkoj čkkaonici & 25.8 & 19.2 & 19.5 & 9.6 & 25.5 & 0.3 \\
\hline
\end{tabular}

Tablica 1 Izjave ispitanika/ca o isključivanju (bešumna opcija) mobitela u specifičnim situacijama i prostorima

Kako je i iz rezultata razvidno, ispitanici poštuju pravila prikladnog ponašanja u prostorima kao što su kazalište, kino, škola/ fakultet, crkva, avion, te u specifičnim situacijama kao što su

51 Ling R., „One can talk about common manners!“: the use of mobile telephones in inappropiate situations, in: Themes in mobile telephony Final Report of the COST 248 Home and Work group, eds. Haddon L., 1997, str.1. 
sprovodi i važni školski/poslovni sastanci. Također možemo primjetiti da se ispitanici/e najmanje prikladno ponašaju u vezi korištenja mobitela, za vrijeme obroka s drugima (restoran), te $\mathrm{u}$ lječničkoj čekaonici i knjižnici. Obzirom da ispitanici/e najmanje poštuju pravila lijepog ponašanja za vrijeme obroka s drugima ili u prostorima kao što je restoran, pobliže ćemo objasniti specifičan prostor restorana i sukladno tome potrebu i zahtjev prikladnog ponašanja za vrijeme boravka u njemu.

\section{Primjer restorana}

Restoran je specifični prostor za koji vrijede postojeća brojna pravila lijepog ponašanja, od onoga kako se služiti priborom za jelo do toga kako razgovarati s poslugom. Sukladno tome, korištenje mobilnog telefona $u$ restoranu postala je metafora za neprikladno i nekulturno ponašanje. Iz društvene perspektive, restoran je prostor kojim se netko privremeno koristi, te je istovremeno i javni, ali i privatni prostor osobe ili grupe ljudi. ${ }^{52}$ Stol, separe, pribor za jelo koje neki gost zauzima, postaju njegovim unutar razdoblja korištenja. Imamo pravo potpuno ignorirati osobe koje nas okružuju, iako se nalaze na maloj udaljenosti. Gosti osjećaju privatnost za svojim stolovima, iako je ona manje ili više otvorena za druge. Goffman naglašava kako se u restoranima razgraničavanje najčešće postiže arhitekturom i razmještajem namještaja koje stabilizira polaganje prava na prostor. Ovakva pravila dopuštaju građenje jasno primjetnih granica između pojedinaca i grupa koji mogu jasno definirati gdje privremeno pripadaju, te odrediti očekivanja o tome što je drugim gostima dozvoljeno, odnosno nije dozvoljeno obzirom na njih. U kontekstu toga, zanimljivo je promotriti kako mobitel narušava ovaj osobno/javni prostor.

Jedna od temeljnih objektivizacija mobilnih telefona u svezi je sa zvukovima. Kada je riječ o „modalitetima nasilja“ osobnog prostora, Goffman ${ }^{53}$ govori o ,interferenciji zvukova“. Različiti su zvukovi koji u restoranu mogu stvoriti smetnju drugima, primjerice preglasno pričanje, podrigivanje, glasno žvakanje hrane, roditelji s glasnom djecom i slično. U skupinu neprilagođenih zvukova dakako spada i zvonjava mobitela, bez obzira na jačinu volumena zvona. Zvuk zvona na mobitelu, a posebice zvuk dolazeće SMS poruke, po svojoj prirodi je ometajući zvuk, koji prisiljava osobu da ga čuje i usredotoči se na njega. Također zbog sve prožimajuće upotrebe mobitela, sama zvonjava uzrokuje potrebu da svi oni koji imaju mobilne telefone provjeravaju zvoni li njihov mobitel, što ima ometajući učinak na osobu,

52 Ibid., str. 7.

53 Ibid., str. 9-10. 
prekidajući time sve ono što je do tada radila. Sama zvonjava mobitela, dovodi nas do onoga što nakon nje slijedi, a jednako je neugodno i neprikladno, a to je telefonska konverzacija. Osim što će osoba koja razgovara na mobitel izići iz socijalnog konteksta u kojem je do tada bila i time se početi sasvim drugačije ponašati, njezina konverzacija narušava, osim njezinog osobnog prostora, osobni prostor drugih koji se oko nje nalaze. Obzirom da u telefonskoj konverzaciji osoba ne može vidjeti vizualne geste druge osobe, njezin govor tijela i facijalnu ekspresiju, ono se onda zamjenjuje verbalnim gestama, kao što su: stalne promjene u intonaciji, pauze, naglašavanje. Korištenje tonova kao što su „uh“, zamjenjujući time vizualni kontakt koji kontrolira trenutak prebacivanje konverzacije, frazom "ah ha" zamjenjujemo ono što bi u konverzaciji licem u lice, bilo klimanje glavom kao znak odobravanja. Također je telefonska konverzacija uvijek glasnija, zbog potrebe nadglasavanja pozadinske buke. Osim što mobitel narušava osobni prostor drugih ljudi u restoranu, osoba koja razgovara na mobitel, mora djelovati unutar dva paralelna prostora, prostor konverzacije i fizičkog prostora prisutnosti, što naravno izaziva veliki stres i kod osobe koja razgovara i onih koji sjede s njom za stolom.

\section{Zaključak}

Prisutnost mobitela unutar naših svakodnevnih života postaje nezaobilazna činjenica. Njegova uporaba koja je poprimila neslućene razmjere, upućuje na društvenu i socijalnu ovisnost o njima. Naime, gotovo sve dnevne aktivnosti ovise $\mathrm{i}$ isprepletene su mobilnom komunikacijom i ostalim sredstvima nove tehnologije. U tom smislu, znanstveno-empirijska istraživanja poput ovoga idu prema razumijevanju kulturalnih i društvenih značenja ovog novog medija, koja su mnogo dublja i šira od njegove primarne funkcije kao komunikacijskog alata.

Provedeno istraživanje potvrdilo je veliki značaj i utjecaj mobitela na obrasce svakodnevnog života mladih u smislu izravnog utjecaja na promjene temeljnih komunikacijskih obrazaca $i$ svakodnevnih aktivnosti. Mladi se smatraju začetnicima u adaptaciji i prilagodbi korištenja specifičnog načina komuniciranja putem SMS poruka koja među njima postaje najprihvaćeniji oblik interakcije. Nadalje, jedna od značajki korištenja mobilne komunikacije manifestira se u modifikaciji uvriježenih obrazaca prostora i vremena. Dolazi do odvajanja od konkretnog prostora $\mathrm{u}$ kojem se pojedinac koji komunicira trenutno nalazi, pa smo u mogućnosti ustanoviti kako se netko ne nalazi negdje, iz razloga što je nemoguće provjeriti je li netko stvarno negdje. Ovdje, sada, tu sam, nisam tu, poprimaju obilježja društveno konstruiranih kontekstualnih mjesta postojanja koja se oblikuju s obzirom 
na trenutne aspiracije, potrebe i ideje korisnika mobilnog uređaja. Granice između privatnog i javnog postaju sve nevidljivije i fluidnije, što vodi prema redefiniranju prikladnog i neprikladnog društvenog ponašanja u javnom prostoru.

\section{LITERATURA:}

Afrić V., Kibernetski prostor i virtualna realnost kao društvena upotreba informacijskih i komunikacijskih tehnologija, Revija za sociologiju br. 3-4, Zagreb 1999, str. 181-194.

Arminen I., Review Essay Mobile Communication Society?, Acta Sociologica br. 4, Nordic Sociological Association and SAGE 2007, str. 431-437.

Balakrishnan V., Yeow P.H.P., Texting Satisfaction: Does Age and Gender Make a Difference?, International Journal of Computer Science and Security br. 1, Kuala Lumpur 2007, str. 85-96.

Campbell M. A., The impact of the mobile phone on young people's social life, in: Social Change in the 21st Century Conference, Brisbane 2005.

Caronia L., Mobile culture: An etnography of cellulare phone uses in teenagers everday life, Convergence br. 3, SAGE Publication 2005, str. 96-103.

Castells M., Informacijsko doba: ekonomija, društvo i kultura: Uspon umrě̌enog društva, Zagreb 2000.

Castells M., Fernandez-Ardevol M., Qiu J. L. i Sey A., Mobile communication and society: a global perspective, Cambridge 2007.

Čaldarović O. i Šarinić J., Suvremena komunikacijska tehnologija i urbana sredina - prostor, mjesta, vrijeme, Socijalna ekologija br. 4, Zagreb 2008, str. 331-341.

Giddens A., Sociologija, Zagreb 2007.

Gordon J., The Mobile Phone - An Artefact of Popular Culture and a Tool of the Public Sphere, Convergence br. 3, SAGE Publication 2002, str. 15- 26.

Hawk B., Rieder D. M. i Oviedo O., Small Tech: The Culture of Digital Tools, Minnesota 2008.

Ivas I. i Žaja L., Znakovi usmene komunikacije u pisanoj komunikaciji na IRC-u i ICQ-u, Medijska istraživanja br. 1, Zagreb 2003, str. 77-97.

Krotz F., The meta-process of „mediatization“ as a conceptual frame, Global Media and Communication br. 3, SAGE Publication 2007, str. 256- 260.

Laniado N. i Pietra G., Naše dijete, videoigre, Internet i televizija (Što učiniti ako ga hipnotiziraju?), Rijeka 2005.

Leburić A. i Nigoević M., Mediji kao (pre)nositelji interkulturalizma u hrvatsko-talijanskim interakcijama: istraživanja s početka trećeg 
milenija, Split 2008.

Leburić A., Quien M. i Lovrić D., Stari i novi mediji: sociološko istraživanje medijskog stiliziranja života, Split 2008.

Ling R., „One can talk about common manners!“: the use of mobile telephones in inappropiate situations, in: Themes in mobile telephony Final Report of the COST 248 Home and Work group, eds. Haddon L., 1997.

Ling R., The socio-linguistics of SMS: An analysis of SMS use by a random sample of Norwegians, in: Mobile communications: Renegotiation of the social sphere, eds. R. Ling i P. Pedersen, London 2005.

Mandarić V. B., Mladi integrirani i (li) marginalizirani, Zagreb 2009.

McLeod E., The Use (and Disuse) of Mobile Phones by Baby Boomers, International Journal of Emerging Technologies and Society br. 1, Hawthorn 2009, str. 28-38.

Miliša Z., Manipuliranje potrebama mladih, Zagreb 2006.

Miliša Z., Tolić M. i Vertovšek N., MEDIJI I MLADI prevencija ovisnosti o medijskoj manipulaciji, Zagreb 2009.

Monk A., Fellas E. i Ley E., Hearing only one side of normal and mobile phone conversations, Behaviour \& Information Technology br. 5, Taylor \& Francis 2004, str. 301-305.

Panian Ž., Informatički enciklopedijski rječnik M-Z, Zagreb 2005.

Rafi M. S., SMS Text analysis: Language Gender and Current Practices, Language Vitality in South Asia, Aligarh, Department of Linguistics, Aligarh Muslim University Press, India 2009, str. 393-405.

Rettie M. R., Presence and Embodiment in Mobile Phone Communicatin, PsychNology Journal br. 1, 2005, str. 16-34.

Sindik J. i Reicher K., Internet kao sredstvo za ostvarivanje ,intimnije“ komunikacije. Metodički ogledi br. 2, Zagreb 2008, str. 83-100.

Šunić N., Komunikacija mladih putem SMS-a, Zdrav život br. 74-75, Zagreb 2009.

Thulin E. i Vilhelmson B., Mobile everywhere - Youth, the mobile phone, and changes in everyday practice, Young: Nordic Journal of Youth Research br. 3, Copenhagen 2007, str. 235-253.

Tomić Z., Komunikacija i javnost, Beograd 2004.

Truch A., Exploring the implications for social identify of the new sociology of the mobile phone, The global and local in Mobile Communication: Places, Images, people, and connections, Budimpešta 2004

Tutt D., Mobile Performances of a Teenager: A study of Situated Mobile Phone Activity in the Living Room, Convergence: The International Journal of Research into New Media Technologies br. 2, SAGE Publication 2005, str. 8-75.

Zerubavel E., Privatno i javno vrijeme, III Program hrvatskog radija br. 42, Zagreb 1993, str. 14- 33. 
TINA BOŽIĆ i RENATA RELJA

Tina Božić and Renata Relja

University of Split, Faculty of Philosophy -

Department of Sociology, Split, Croatia

\title{
THE NEW CULTURE OF COMMUNICATION VIA MOBILE PHONES AMONG YOUNG PEOPLE
}

\begin{abstract}
This paper presents results of an empirical research analysing aspects of mobile phone use among young people and its impact on everyday social life, communication and social interaction. The mobile phone cannot be reduced to a mere material object, a functional and practical product of global society, but it also has an important social and cultural dimension and needs to be studied systematically. The main focus of our theoretical and research efforts is the sociological and cultural phenomenon of the mobile phone use among young people, and its impact on everyday social life, social relations, patterns of activity, communication and interaction, emphasizing the relationship between the individual and mobile telephony. This paper examines creation of a new culture of communication where the phenomen is explained by texting, creation of new linguistic forms, emphasizing redefinition of traditional notions of time and place, creation of new spaces such as conversational space. It also considered concepts of the private and the public, in relation to notions of the socially acceptable and the unacceptable. The study was carried out using a structured questionnaire on a sample of 302 respondents in the target area of Split and the surrounding places. The field phase of the research was conducted during May and June 2010. Young people were selected as the target research population because they are thought to be "pioneers" in the use of information and computer technologies. Information and communication technologies in general and mobile telephony in particular have become a youth technology. Young people are the largest group of consumers of mobile technology and are often considered to be pioneers in their adaption and evolution.
\end{abstract}

Key words: mobile technology, communication, youth, SMS, timespace, public-private 